\title{
Persistence of an outbreak of gonorrhoea with high-level resistance to azithromycin in England, November 2014- May 2018
}

Christa Smolarchuk ${ }^{1,3}$, Adrian Wensley ${ }^{2,3}$, Simon Padfield ${ }^{2}$, Helen Fifer ${ }^{4}$, Andrew Lee ${ }^{5}$, Gwenda Hughes ${ }^{1}$

1. HIV \& STI Department, Public Health England, Colindale, London, United Kingdom

2. Field Epidemiology Service, Public Health England, Leeds, United Kingdom

3. These authors contributed equally to this work and share first authorship

4. Bacteriology Reference Department, National Infection Service, Public Health England, Colindale, London, United Kingdom

5. Public Health England, Yorkshire and Humber, Leeds

Correspondence: Christa Smolarchuk (christa.smolarchuk@gov.ab.ca)

Citation style for this article:

Smolarchuk Christa, Wensley Adrian, Padfield Simon, Fifer Helen, Lee Andrew, Hughes Gwenda. Persistence of an outbreak of gonorrhoea with highlevel resistance to azithromycin in England, November 2014-May 2018. Euro Surveill. 2018;23(23):pii=1800287. https://doi.org/10.2807/1560-7917. ES.2018.23.23.1800287

Article submitted on 30 May 2018 / accepted on 07 Jun 2018 / published on 07 Jun 2018

Between November 2014 and May 2018, 118 laboratory-confirmed cases of high-level azithromycin resistant Neisseria gonorrhoeae were identified in England. Cases emerged among heterosexuals in Leeds but spread across England and into sexual networks of men who have sex with men as the outbreak progressed. The few epidemiological links identified indicate substantial under-diagnosis of cases and this, along with the upturn in cases in 2017, highlights the difficulties in controlling the outbreak.

An outbreak of high-level azithromycin resistant Neisseria gonorrhoeae (HL-AziR; minimum inhibitory concentration (MIC) $\geq 256 \mathrm{mg} / \mathrm{L}$ ) was first identified in Leeds in the north of England in 2015, where a local incident control team was convened [1-3]. This transitioned into a national response in early 2016 as increasing numbers of cases were identified in other parts of the country. The outbreak is still ongoing, despite a number of interventions, including increasing awareness among clinicians and microbiologists, a national resistance alert issued by Public Health England (PHE) [4], and intensive follow-up of cases and their partners through partner notification (PN) by sexual health services. This report provides an update on the epidemiology of HL-AziR cases in England and describes the progression of the outbreak up to May 2018.

\section{Description of the outbreak}

Between November 2014 and May 2018, 118 laboratory confirmed cases of HL-AziR were identified in England. Despite concerns of rapid escalation and spread, the average number of new cases identified per month remained relatively stable initially, but cases per month increased from 2.6 in 2015 to 3.3 in 2017 and 3.4 in 2018 (Figure 1). There was one reported treatment failure in early 2018 , but this infection was likely acquired outside of the United Kingdom (UK) $[5,6]$. This case was also the first global report of an isolate that had HL-AziR and was also resistant to ceftriaxone.

The outbreak emerged at the end of 2014 among young heterosexuals (median age 18 years, range 16-53; $\mathrm{n}=15$ ) living in deprived areas in Leeds. No specific risk factors, such as common educational establishments, use of online dating applications (apps), or venues, were identified in the initial investigation. Most heterosexual cases were positive at a single site of infection (46/71), and were predominantly genital infections (41/50), among those where site of infection was known (Table 1). Re-attendance for test of cure among these cases was relatively low (10/15), even with intensive follow-up of cases, and clinicians reported difficulty in identifying partners.

Cases spread geographically (Figure $1 \mathrm{~A}$ ) and into sexual networks of men who have sex with men (MSM) (Figure 1B) as the outbreak progressed. Cases among MSM were first identified in November 2015 mainly from a large, high-throughput clinic in London, which serves a substantial MSM population. Of the 36 cases identified among MSM, seven were known to be HIVpositive (Table 1). MSM cases were generally older than heterosexual cases (median age 30 years, range 17-65) but also lived in deprived areas. Only a few MSM reported using apps or websites to meet sex partners, but this might be under-reported. Among MSM, most had a single site of infection (12/20), but the most common site of infection was pharyngeal (13/20) (Table 1$)$. Re-attendance for test of cure was higher among MSM (31/36) compared with heterosexuals. 


\section{FIGURE 1}

Confirmed cases of high-level azithromycin resistant Neisseria gonorrhoeae by (A) area of residence and (B) sexual orientation, England, November 2014 and May 2018 ( $\mathrm{n}=118)$

A.

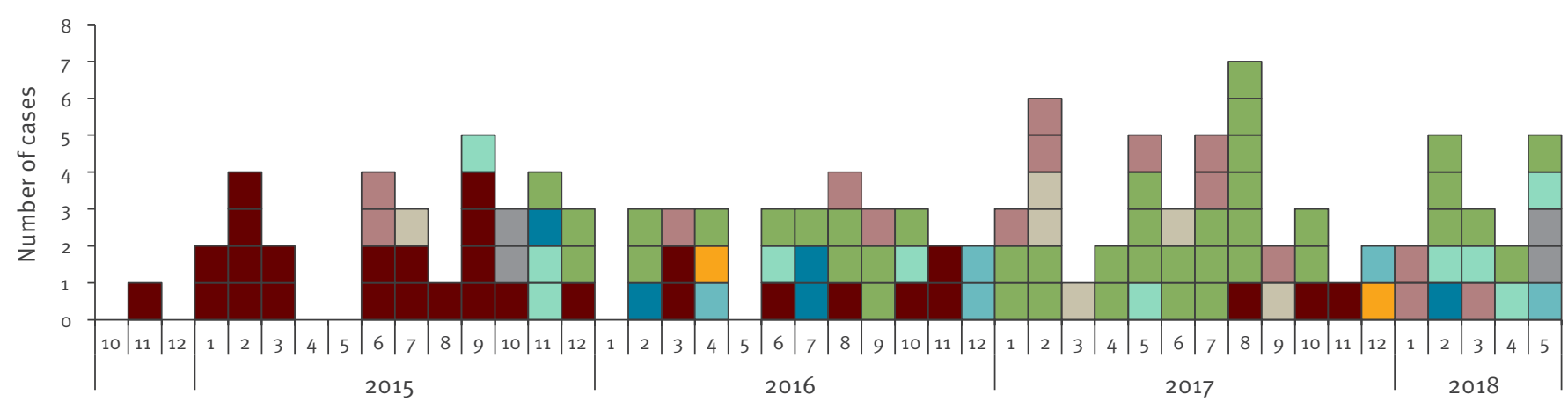

Month and year of clinic visit

$\begin{array}{lll}\square & \text { East Midlands } & \text { East of England } \\ \square \text { North East } & \text { North West } & \square \text { South East } \\ \square \text { West Midlands } & \text { Yorkshire and the Humber } & \square \text { South West }\end{array}$

B.

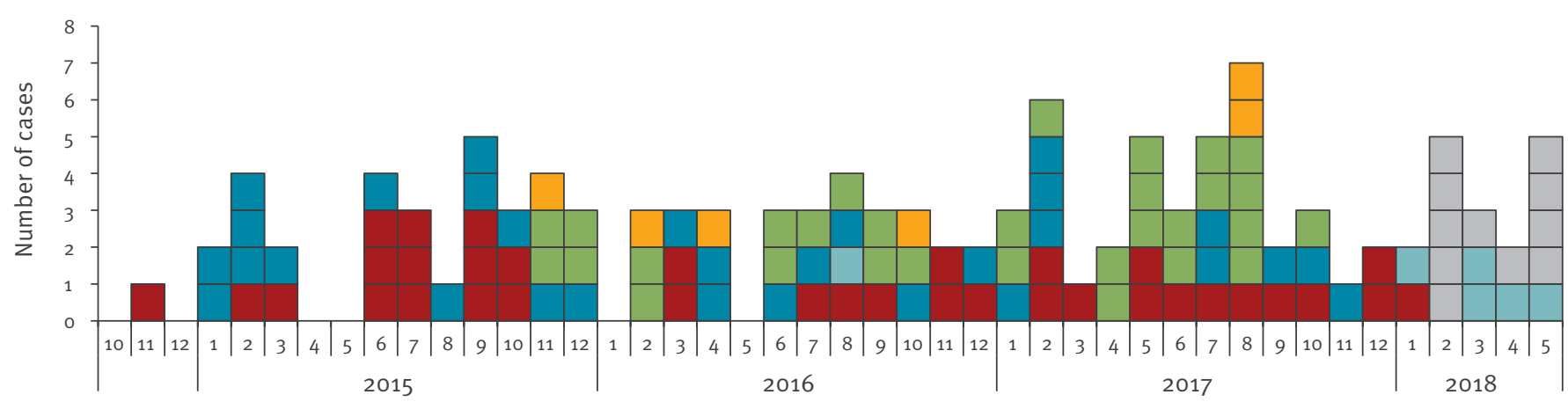

Month and year of clinic visit

$\begin{array}{lll}\square \text { Male Gay } & \text { Male Heterosexual } & \text { Male Unknown } \\ \text { Male Bisexual } & \text { Female Heterosexual } & \text { F Female Unknown }\end{array}$

Data for end of May 2018 could be incomplete as there is a lag time of 2 to 3 weeks in antimicrobial susceptibility testing.

a Public Health England Centre.

\section{Sexual partnerships and transmission networks}

Six cases among MSM also exhibited bisexual behaviour suggesting a degree of fluidity between sexual networks, which may have facilitated more rapid and widespread transmission. Partner information was reported through enhanced surveillance for $82 \%$ $(83 / 101)$ of cases up to December 2017 (52 heterosexual and 31 MSM). The median number of partners in the previous 3 months reported per case was two among MSM (range 1-20 partners) and 1.5 among heterosexuals (range 1-11 partners). There were very few direct links identified between heterosexual cases (Figure 2A) and no direct links identified between any MSM cases (Figure 2B). Among 52 heterosexual cases, 25 were epidemiologically linked to another case establishing 11 separate transmission networks (the largest linking four early Leeds cases).

\section{Partner notification and case ascertainment} Effective PN is essential to controlling STI-related outbreaks, but despite best efforts by clinic staff, success was limited. Only 35\% (33/95) of partners reported 
Characteristics and demographics of laboratory-confirmed cases of high-level azithromycin resistant Neisseria gonorrhoeae, England November 2014 -May 2018

\begin{tabular}{|c|c|c|c|c|c|c|}
\hline \multicolumn{2}{|c|}{ Patient characteristics } & Women & Heterosexual Men & MSM & Men unknown & Total \\
\hline & & \multicolumn{5}{|l|}{$\mathrm{n}(\mathrm{col} \%)$} \\
\hline Total cases (n) & & $41(100)$ & $30(100)$ & $36(100)$ & $11(100)$ & $118(100)$ \\
\hline \multicolumn{7}{|l|}{ Ethnicity } \\
\hline & White & $31(76)$ & $19(63)$ & $24(67)$ & $\mathrm{o}(\mathrm{o})$ & $74(63)$ \\
\hline & Black & $\mathrm{o}(\mathrm{o})$ & $5(17)$ & $6(17)$ & $\mathrm{o}(0)$ & $11(9)$ \\
\hline & Other & $2(5)$ & $5(17)$ & $6(17)$ & o (o) & $13(11)$ \\
\hline & Unknown & $8(20)$ & $1(3)$ & o (o) & $11(100)$ & $20(17)$ \\
\hline \multicolumn{7}{|c|}{ Age group (years) } \\
\hline & $15-19$ & $21(51)$ & $9(30)$ & $4(11)$ & $1(9)$ & $35(30)$ \\
\hline & $20-24$ & $14(34)$ & $8(27)$ & $6(17)$ & $2(18)$ & $30(25)$ \\
\hline & $25-34$ & $5(12)$ & $8(27)$ & $14(39)$ & $5(45)$ & $32(27)$ \\
\hline & $\geq 35$ & $1(2)$ & $5(17)$ & $12(33)$ & $3(27)$ & $21(18)$ \\
\hline & Yes & $28(68)$ & $24(80)$ & $24(67)$ & o (o) & $76(64)$ \\
\hline & No & $2(5)$ & 310() & $11(31)$ & $\mathrm{o}(\mathrm{o})$ & $16(14)$ \\
\hline & Unknown & $11(27)$ & $3(10)$ & $1(3)$ & $11(100)$ & $26(22)$ \\
\hline \multicolumn{7}{|c|}{ World region of birth } \\
\hline & UK & $28(72)$ & $24(80)$ & $24(67)$ & o (o) & $76(68)$ \\
\hline & Other & $2(5)$ & $3(10)$ & $11(31)$ & o (o) & $16(14)$ \\
\hline & Unknown & $9(23)$ & $3(10)$ & $1(3)$ & $6(100)$ & $19(17)$ \\
\hline \multicolumn{7}{|l|}{ HIV status } \\
\hline & Positive & $\mathrm{o}(\mathrm{o})$ & $\mathrm{o}(\mathrm{o})$ & 7 (19) & $0(0)$ & $7(6)$ \\
\hline & Negative/Undiagnosed & $27(66)$ & $25(83)$ & $27(75)$ & $\mathrm{o}(0)$ & $79(67)$ \\
\hline & Unknown & $14(34)$ & $5(17)$ & $2(6)$ & $11(0)$ & $32(27)$ \\
\hline \multicolumn{7}{|c|}{ Index of multiple deprivation } \\
\hline & Most deprived & $13(32)$ & $11(37)$ & $7(19)$ & $\mathrm{o}(0)$ & $31(26)$ \\
\hline & 2nd most deprived & $5(12)$ & $2(7)$ & $16(44)$ & $\mathrm{o}(\mathrm{o})$ & $23(19)$ \\
\hline & 3rd most deprived & $2(5)$ & $2(7)$ & 7 (19) & $\mathrm{o}(\mathrm{o})$ & $11(9)$ \\
\hline & 4th most deprived & $2(5)$ & $5(17)$ & $3(8)$ & $0(0)$ & $10(8)$ \\
\hline & Least deprived & $4(10)$ & $3(10)$ & $1(3)$ & $\mathrm{o}(\mathrm{o})$ & $8(7)$ \\
\hline & Unknown & $15(37)$ & $7(23)$ & $2(6)$ & $11(100)$ & $35(30)$ \\
\hline
\end{tabular}

by heterosexual cases and $0 \%(0 / 153)$ of partners reported by MSM cases were verified by sexual health services as successfully contacted and tested (Table 2). Among the partners who were tested, 14 of 29 were confirmed as new cases. Most of the reported partners were uncontactable because contact details were not disclosed by cases or were unavailable for casual partners. In the absence of effective PN, high frequency of asymptomatic infection is likely to further contribute to sustained transmission; up to December 2017, 15 of 36 MSM, 4 of 30 heterosexual men, and 18 of 35 women were asymptomatic (Table 1). Among the four linked heterosexual cases in Leeds, one became re-infected, further highlighting the potential impact of untreated partners on spread of the outbreak.

All cases were confirmed as high-level azithromycin resistant by PHE's national reference laboratory. An estimated $63 \%$ of all gonorrhoea diagnosed in England are cultured for antimicrobial susceptibility testing [7]. On multiple occasions, PHE attempted to improve the rate of referral of gonococcal isolates with suspected resistance, identified by primary diagnostic laboratories to
PHE's national reference laboratory for confirmatory antimicrobial susceptibility testing. Referrals of gonococcal isolates with suspected azithromycin resistance increased from 34\% (96/282) to 50\% (219/437) and gonococcal isolates with suspected ceftriaxone resistance increased from 27/89 isolates to $14 / 41$ in 2015 and 2017 (up to October), respectively, but remained suboptimal overall [8]. Issues related to low referrals rates by primary diagnostic laboratories included a lack of standard processes and staff awareness to ensure that isolates were referred, often exacerbated by high staff turn-over and difficulty with retrieval of cultures for transport to the national reference laboratory.

\section{Discussion and conclusions}

There has been sustained transmission of HL-AziR in England since November 2014. Few cases had identified epidemiological links and this, along with the limited effectiveness of PN, suggests there is likely a considerable reservoir of undiagnosed infection fuelling transmission. Despite the lack of direct links identified between most cases, the early geographic clustering, and multiple bisexual cases potentially linking heterosexual and MSM sexual networks, strongly suggested 
Characteristics and demographics of laboratory-confirmed cases of high-level azithromycin resistant Neisseria gonorrhoeae, England November 2014 -May 2018

\begin{tabular}{|c|c|c|c|c|c|c|}
\hline \multicolumn{2}{|c|}{ Patient characteristics } & Women & Heterosexual Men & MSM & Men unknown & Total \\
\hline & & \multicolumn{5}{|l|}{ n (col \%) } \\
\hline Enhanced data on cases (n) ${ }^{a}$ & & $35(100)$ & $30(100)$ & $36(100)$ & $0(100)$ & $101(100)$ \\
\hline \multicolumn{7}{|l|}{ Symptoms ${ }^{b}$} \\
\hline & Discharge and/or Dysuria & $13(37)$ & $25(83)$ & $19(53)$ & o & $57(56)$ \\
\hline & No Discharge and/or Dysuria & $18(51)$ & $4(13)$ & $15(42)$ & 0 & $37(37)$ \\
\hline & Unknown & $4(11)$ & $1(3)$ & $2(6)$ & 0 & $7(7)$ \\
\hline \multicolumn{7}{|l|}{ Site(s) positive ${ }^{b, c}$} \\
\hline & Genital & $21(60)$ & $25(83)$ & $9(25)$ & 0 & $55(54)$ \\
\hline & Rectal & $5(14)$ & o (o) & $8(22)$ & o & $13(13)$ \\
\hline & Throat & $7(20)$ & $1(3)$ & $13(36)$ & o & $21(21)$ \\
\hline & Other & $1(3)$ & $1(3)$ & o (o) & 0 & $2(2)$ \\
\hline & Unknown sites & $11(31)$ & $4(13)$ & $16(44)$ & 0 & $31(31)$ \\
\hline \multicolumn{7}{|l|}{ Multiple/single site(s) ${ }^{b, c}$} \\
\hline & Single site & $16(46)$ & $25(83)$ & $12(33)$ & 0 & $53(53)$ \\
\hline & Multiple sites & $8(23)$ & $1(3)$ & $8(22)$ & 0 & $17(17)$ \\
\hline & Unknown sites & $11(31)$ & $4(13)$ & $16(44)$ & 0 & $31(31)$ \\
\hline \multicolumn{7}{|l|}{ Test of cure } \\
\hline & Yes & $20(57)$ & $18(60)$ & $31(86)$ & 0 & $69(68)$ \\
\hline & No & $11(31)$ & $11(37)$ & $4(11)$ & o & $26(26)$ \\
\hline & Unknown & $4(11)$ & $1(3)$ & $1(3)$ & 0 & $6(6)$ \\
\hline \multicolumn{7}{|l|}{ Partners (past 3 months) } \\
\hline & $0-1$ & $14(40)$ & $12(40)$ & $6(17)$ & o & $32(32)$ \\
\hline & $2-5$ & $11(31)$ & $14(47)$ & $16(44)$ & o & $41(40)$ \\
\hline & $6-10$ & $\mathrm{o}(\mathrm{o})$ & $\mathrm{o}(\mathrm{o})$ & $6(17)$ & o & $6(6)$ \\
\hline & $11+$ & o (o) & $1(3)$ & $3(8)$ & 0 & $4(4)$ \\
\hline & Unknown & $10(29)$ & $3(10)$ & $5(14)$ & 0 & $18(18)$ \\
\hline \multicolumn{7}{|l|}{ Venues (past month) ${ }^{d}$} \\
\hline & Yes & $\mathrm{o}(\mathrm{o})$ & $\mathrm{o}(\mathrm{o})$ & $3(8)$ & 0 & $3(3)$ \\
\hline & No & $\mathrm{o}(\mathrm{o})$ & $\mathrm{o}(0)$ & $1(3)$ & 0 & $1(1)$ \\
\hline & Unknown & $35(100)$ & $30(100)$ & $32(89)$ & 0 & $97(96)$ \\
\hline \multicolumn{7}{|l|}{ Websites (past month) } \\
\hline & Yes & $\mathrm{o}(\mathrm{o})$ & $\mathrm{o}(\mathrm{o})$ & $2(6)$ & 0 & $2(2)$ \\
\hline & No & $0(0)$ & $\mathrm{o}(0)$ & $3(8)$ & 0 & $3(3)$ \\
\hline & Unknown & $35(100)$ & $30(100)$ & $31(86)$ & 0 & $96(95)$ \\
\hline
\end{tabular}

Source: GUMCAD STI Surveillance System and enhanced surveillance of cases. STI: sexually transmitted infection; UK: United Kingdom.

a Data from enhanced surveillance on all cases up to March 2017 only $(n=71)$.

${ }^{b}$ Abbreviated enhanced surveillance only for cases April to December $2017(n=30)$.

c Patients may not have been tested for all sites.

${ }^{d}$ Refers to sex on premises, venues including saunas and sex clubs.

these cases belonged to a discrete outbreak, which was confirmed by whole genome sequencing (WGS) [9]. WGS of isolates up to February 2017 demonstrated that most of the cases shared a distant common ancestor, and 37 of 60 cases were genetically similar (clonal) [9].

The HL-AziR clonal spread among initial outbreak cases in Leeds [9] may have been facilitated by an identified sexual network including four cases, one of whom also became re-infected and indicated ongoing transmission over several months. A local outbreak control team was convened and the last case was identified in October 2015. A brief resurgence of cases in Leeds in 2016 (one case diagnosed in June and then three cases in October and November) were not identified as having epidemiological links to the initial outbreak cases. WGS demonstrated that the isolates from the later cases had evolved, but were still closely related, 
Partner network diagram of laboratory confirmed cases of high-level azithromycin resistant Neisseria gonorrhoeae and their reported partners by (A) heterosexual and (B) men who have sex with men (MSM) cases, England, November 2014 to December $2017(\mathrm{n}=324)$

A. Heterosexual
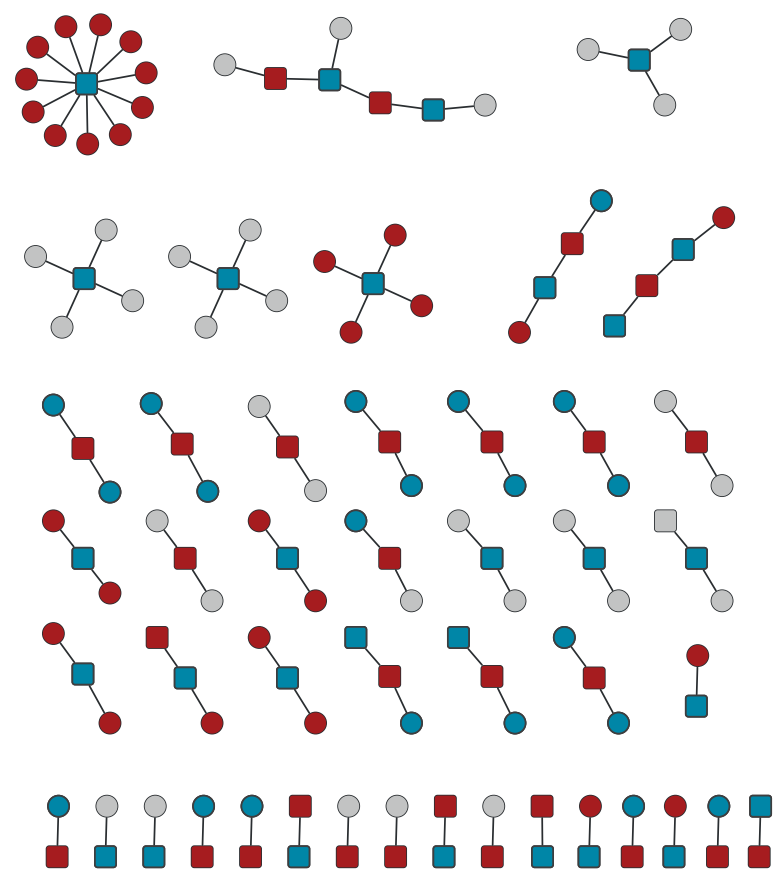

B. MSM

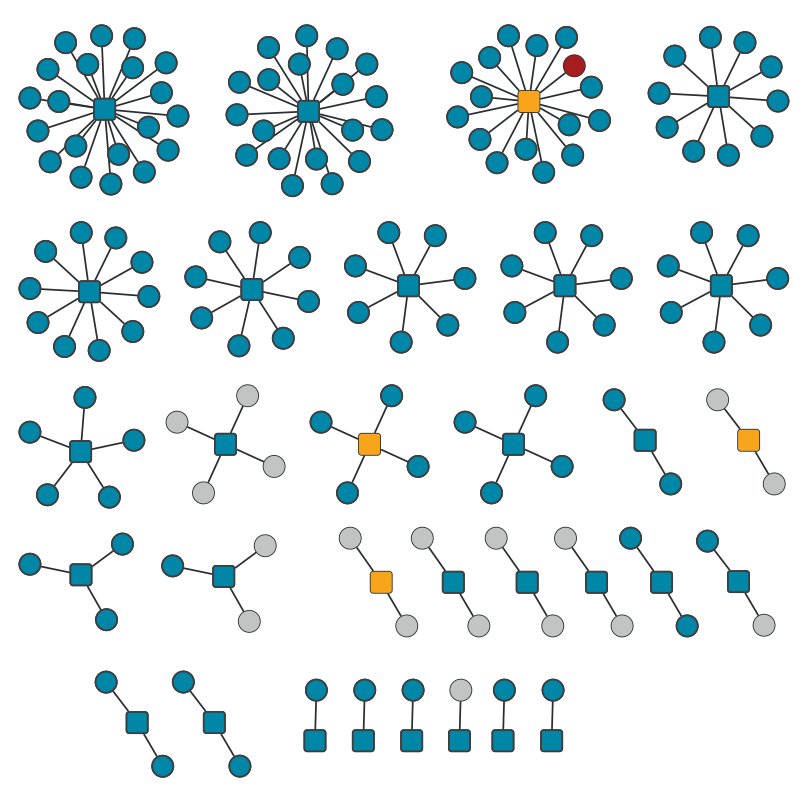

Shape

Contact

Case
Colour

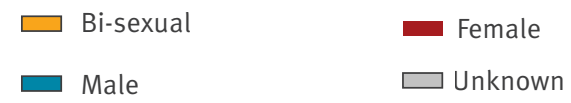

Black lines connecting shapes indicate cases and/or partners with known epidemiological links.

genetically [9]. This suggests that even with the decline in cases in Leeds, the strain continued to circulate.

Gonorrhoea treatment guidelines published by the World Health Organisation (WHO), the UK, Europe and many other countries recommend first-line dual therapy with ceftriaxone and azithromycin to treat gonorrhoea $[10,11]$ in an attempt to delay the development of resistance to ceftriaxone, which despite sporadic reports, remains rare $[12-17]$. While low-level azithromycin resistance $(0.5 \mathrm{mg} / \mathrm{L}<\mathrm{MIC}<256 \mathrm{mg} / \mathrm{L})$ in gonorrhoea is increasing in many countries [18], HL-AziR cases have previously been uncommon or have belonged to small contained outbreaks $[19,20]$, suggesting that HL-AziR may lead to a fitness cost. The data presented here tend not to support this view, although information on population-wide transmission dynamics of different gonococcal strains is sparse [21].
The outbreak received substantial national and local media attention, and multiple communications aimed at providing advice and improving awareness among primary diagnostic laboratories and sexual health services were undertaken. However, the limited effectiveness of PN and poor re-attendance for test of cure, even with intense follow-up, severely hampered control efforts. Referral of suspected azithromycin-resistant gonococcal isolates by primary diagnostic laboratories for confirmatory testing by PHE's national reference laboratory remains sub-optimal.

The increase in HL-AziR cases during 2017, predominantly in MSM in London, demonstrates how an outbreak of gonorrhoea can spread geographically, and within and between sexual networks, even with intensive interventions in place. The outbreak highlights the potential for rapid transmission of highly resistant or even untreatable strains of gonorrhoea in the future. 
Outcomes of partners notified by high-level azithromycin resistant Neisseria gonorrhoeae (HL-AziR) cases verified by sexual health clinics, England, November 2014-December $2017(\mathrm{n}=83)$

\begin{tabular}{|c|c|c|c|}
\hline \multirow[t]{2}{*}{ Partner notification } & Heterosexual & $\begin{array}{l}\text { Men who have sex with } \\
\text { men }\end{array}$ & Total \\
\hline & $\mathrm{n} / \mathrm{N}$ & $\mathrm{n} / \mathrm{N}$ & $\mathrm{n} / \mathrm{N}$ \\
\hline \multicolumn{4}{|l|}{ Partners } \\
\hline Reported by cases & $95 / 95$ & $153 / 153$ & $248 / 248$ \\
\hline \multicolumn{4}{|l|}{ Partner notification } \\
\hline Successfully contacted/verified by sexual health clinic & $33 / 95$ & $0 / 153$ & $33 / 248$ \\
\hline \multicolumn{4}{|l|}{ Gonorrhoea testing } \\
\hline Tested & $29 / 33$ & o & $29 / 33$ \\
\hline Not tested/Unknown & $4 / 33$ & o & $4 / 33$ \\
\hline \multicolumn{4}{|l|}{ Test result } \\
\hline Gonorrhoea positive & $21 / 29$ & o & $21 / 29$ \\
\hline Gonorrhoea negative & $8 / 29$ & o & $8 / 29$ \\
\hline \multicolumn{4}{|l|}{ Partners who became cases } \\
\hline Confirmed case & $14 / 21$ & o & $14 / 21$ \\
\hline Probable case ${ }^{a}$ & $3 / 21$ & o & $3 / 21$ \\
\hline Non-cases ${ }^{\text {b }}$ (gonorrhoea positive; sensitive to azithromycin) & $4 / 21$ & o & $4 / 21$ \\
\hline
\end{tabular}

a Gonorrhoea-positive, partner of a HL-AziR case, no azithromycin sensitivity available.

${ }^{\mathrm{b}}$ Gonorrhoea-positive, isolate sensitive to azithromycin.

Research to identify effective approaches to encourage and empower people to get tested for STIs and to identify barriers to accessing healthcare are urgently required in order to implement unified, enhanced strategies in the prevention of gonorrhoea.

\section{Acknowledgements}

We would like to thank the local Leeds outbreak control team Leeds Genitourinary Medicine Clinic and Health Protection team for their work in the early stages of the outbreak (in particular Dr Janet Wilson and Barbara Davies from the Centre for Sexual Health, Leeds); the national outbreak control team, Health Protection teams and Field Epidemiological Services at Public Health England for their work on the outbreak; all Genitourinary Medicine Clinics for providing enhanced data and routinely submitting data to GUMCAD (and Dr Nneka Nwokolo from the Chelsea and Westminster NHS Foundation Trust); the laboratory staff of Public Health England; and all microbiology laboratories for submitting isolates to the Public Health England national reference service.

\section{Conflict of interest}

None declared.

\section{Authors' contributions}

CS, AW and SP contributed to the compilation and analysis of data; CS, and AW drafted the manuscript with significant input from SP, HF, and GH; AL provided information related to the initial outbreak and lead the outbreak control team in Leeds; and all authors

\section{References}

1. Public Health England (PHE). Outbreak of high level azithromycin resistant gonorrhoea in England. Health Protection Report. England: PHE; 2016;10(15). Available from: https://www.gov.uk/government/uploads/system/uploads/ attachment_data/file/516990/hpr1516_gnrrh.pdf

2. Public Health England (PHE). Outbreak of high level azithromycin resistant gonorrhoea in England: an update. Health Protection Report. England: PHE; 2016;10(30). Available from: https://www.gov.uk/government/uploads/system/ uploads/attachment_data/file/552058/hpr3016_hlzrg.pdf

3. Chisholm SA, Wilson J, Alexander S, Tripodo F, Al-Shahib A, Schaefer U, et al. An outbreak of high-level azithromycin resistant Neisseria gonorrhoeae in England. Sex Transm Infect. 2016;92(5):365-7. https://doi.org/10.1136/ sextrans-2015-052312 PMID: 26601852

4. Public Health England (PHE). Resistance Alert: High-level azithromycin resistance in Neisseria gonorrhoeae. England: PHE; 2016. Available from: https://www.gov.uk/government/ uploads/system/uploads/attachment_data/file/518934/HLAzithromycin-resistant-Neisseria-gonorrhoea_20151110.pdf

5. Public Health England (PHE). Update on investigation of UK case of Neisseria gonorrhoeae with high-level resistance to azithromycin and resistance to ceftriaxone acquired abroad. Health Protection Report. England: PHE; 2018. Available from: https://assets.publishing.service.gov.uk/government/ uploads/system/uploads/attachment_data/file/701185/ hpr1418_MDRGC.pdf

6. Public Health England (PHE). UK case of Neisseria gonorrhoeae with high-level resistance to azithromycin and resistance to ceftriaxone acquired abroad. England: PHE; 2018. Available from: https://assets.publishing.service.gov.uk/government/ uploads/system/uploads/attachment_data/file/694655/ hpr1118_MDRGC.pdf

7. Public Health England (PHE). AMR local indicators. England: PHE; 2017. Available from: https://fingertips.phe.org.uk/ profile/amr-local-indicators/data\#page/o/gid/1938132908/ pat/6/par/E39000030/ati/129/are/E38000010

8. Public Health England (PHE). Surveillance of antimicrobial resistance in Neisseria gonorrhoeae: key findings from the Gonococcal Resistance to Antimicrobials Surveillance Programme. England: PHE; 2017. Available from: https://www. gov.uk/government/uploads/system/uploads/attachment_ data/file/651636/GRASP_Report_2017.pdf

9. Fifer H, Cole M, Hughes G, Padfield S, Smolarchuk C, Woodford $\mathrm{N}$, et al. Sustained transmission of high-level azithromycinresistant Neisseria gonorrhoeae in England: an observational 
study. Lancet Infect Dis. 2018;18(5):573-81. https://doi. org/10.1016/S1473-3099(18)30122-1 PMID: 29523496

10. Bignell C, Unemo M, and TheEuropean STI Guidelines Editorial Board. 2012 European guideline on the diagnosis and treatment of gonorrhoea in adults. Int J STD AIDS. 2013;24(2):85-92. https://doi.org/10.1177/0956462412472837 PMID: 24400344

11. World Health Organization (WHO). WHO guidelines for the treatment of Neisseria gonorrhoeae. Geneva: WHO; 2016. Available from: http://apps.who.int/iris/bitstre am/10665/246114/1/9789241549691-eng.pdf?ua=1

12. Lefebvre B, Martin I, Demczuk W, Deshaies L, Michaud S, Labbé A-C, et al. Ceftriaxone-Resistant Neisseria gonorrhoeae, Canada, 2017. Emerg Infect Dis. 2018;24(2):381-3. https://doi. org/10.3201/eid2402.171756 PMID: 29131780

13. de Curraize C, Kumanski S, Micaëlo M, Fournet N, La Ruche G, Meunier F, et al. Ceftriaxone-Resistant Neisseria gonorrhoeae Isolates (2010 to 2014) in France Characterized by Using Whole-Genome Sequencing. Antimicrob Agents Chemother. 2016;60(11):6962-4. https://doi.org/10.1128/AAC.01568-16 PMID: 27600036

14. Ohnishi M, Saika T, Hoshina S, Iwasaku K, Nakayama $\mathrm{S}$, Watanabe $\mathrm{H}$, et al. Ceftriaxone-resistant Neisseria gonorrhoeae, Japan. Emerg Infect Dis. 2011;17(1):148-9. https://doi.org/10.3201/eid1701.100397 PMID: 21192886

15. Fifer H, Natarajan U, Jones L, Alexander S, Hughes G, Golparian $D$, et al. Failure of Dual Antimicrobial Therapy in Treatment of Gonorrhea. N Engl J Med. 2016;374(25):2504-6. https://doi. org/10.1056/NEJMc1512757 PMID: 27332921

16. Scharbaai-Vázquez R, González-Caraballo AL, Torres-Bauzá LJ. Ceftriaxone-resistant Neisseria gonorrhoeae, Puerto Rico. Sex Transm Infect. 2015;91(2):99. https://doi.org/10.1136/ sextrans-2014-051716 PMID: 25253760

17. Cámara J, Serra J, Ayats J, Bastida T, Carnicer-Pont D, Andreu A, et al. Molecular characterization of two high-level ceftriaxoneresistant Neisseria gonorrhoeae isolates detected in Catalonia, Spain. J Antimicrob Chemother. 2012;67(8):1858-60. https:// doi.org/10.1093/jac/dks162 PMID: 22566592

18. Wi T, Lahra MM, Ndowa F, Bala M, Dillon JR, Ramon-Pardo P, et al. Antimicrobial resistance in Neisseria gonorrhoeae: Global surveillance and a call for international collaborative action. PLoS Med. 2017;14(7):e1002344. https://doi.org/10.1371/ journal.pmed.1002344 PMID: 28686231

19. Chisholm SA, Neal TJ, Alawattegama AB, Birley HDL, Howe $\mathrm{RA}$, Ison CA. Emergence of high-level azithromycin resistance in Neisseria gonorrhoeae in England and Wales. J Antimicrob Chemother. 2009;64(2):353-8. https://doi.org/10.1093/jac/ dkp188 PMID: 19468025

20. Papp IR, Abrams AJ, Nash E, Katz AR, Kirkcaldy RD, O'Connor NP, et al. Azithromycin Resistance and Decreased Ceftriaxone Susceptibility in Neisseria gonorrhoeae, Hawaii, USA. Emerg Infect Dis. 2017;23(5):830-2. https://doi.org/10.3201/ eid2305.170088 PMID: 28418303

21. Unemo M, Nicholas RA. Emergence of multidrug-resistant, extensively drug-resistant and untreatable gonorrhea. Future Microbiol. 2012;7(12):1401-22. https://doi.org/10.2217/ fmb.12.117 PMID: 23231489

\section{License and copyright}

This is an open-access article distributed under the terms of the Creative Commons Attribution (CC BY 4.0) Licence. You may share and adapt the material, but must give appropriate credit to the source, provide a link to the licence, and indicate if changes were made.

This article is copyright of the authors, 2018. 